\title{
Infrared Spectroscopic Study on the Modified Mechanism of Aluminum-Impregnated Bone Charcoal
}

\author{
Hao Li, ${ }^{1}$ Yufan Yang, ${ }^{2}$ Shuangjun Yang, ${ }^{3}$ Anpu Chen, ${ }^{1}$ and Dazuo Yang ${ }^{4}$ \\ ${ }^{1}$ College of Chemistry, Sichuan University, Chengdu, Sichuan 610064, China \\ ${ }^{2}$ West China School of Public Health, Sichuan University, Sichuan 610064, China \\ ${ }^{3}$ College of Light Industry, Sichuan University, Chengdu, Sichuan 610064, China \\ ${ }^{4}$ College of Life Science and Technology, Dalian University of Technology, Dalian 116021, China
}

Correspondence should be addressed to Hao Li; lihao_chem_92@hotmail.com

Received 16 May 2014; Accepted 2 June 2014; Published 22 June 2014

Academic Editor: Qingrui Zhang

Copyright (C) 2014 Hao Li et al. This is an open access article distributed under the Creative Commons Attribution License, which permits unrestricted use, distribution, and reproduction in any medium, provided the original work is properly cited.

\begin{abstract}
Fluoride contamination in drinking water is a prominent and widespread problem in many parts of the world. Excessive ingestion of fluoride through water can lead to the high risk of fluorosis in human body. Bone charcoal, with the principal active component of hydroxyapatite, is a frequently used adsorbent for fluoride removal. Many laboratory experiments suggest that the aluminumimpregnated bone charcoal is an effective adsorbent in defluoridation. However, the mechanisms underlying this modification process are still not well understood, which in turn greatly impedes the further studies on other different modified adsorbents. To address this issue, we used the infrared spectroscopy to examine the bone charcoal and the aluminum-impregnated bone charcoal, respectively. The comparative results show that the $-\mathrm{OH}$ peak of infrared spectroscopy has been intensified after modification. This significant change helped speculate the modified mechanism of the aluminum-impregnated bone charcoal. In addition, it is found that the hydroxide ion dissociates from hydroxyapatite in the modification process. Such finding implies that the tetrahydroxoaluminate can be combined with the hydroxyapatite and the aluminum ion can be impregnated onto the bone char surface.
\end{abstract}

\section{Introduction}

Fluoride is widely distributed in nature, which mainly exists in lithosphere, hydrosphere, biosphere, and atmosphere $[1$, 2]. Most fluorides are soluble, even the lowest solubility of calcium fluoride can reach $40 \mathrm{mg} / \mathrm{L}$ in normal condition [3]. The soluble fluorides in rocks can dissolve in water, which are the main sources of the fluorides in fresh water. Therefore, humans obtain fluorides largely from drinking water [4]. There exists about 2 to $3 \mathrm{~g}$ (commonly $2.6 \mathrm{~g}$ ) fluorine in a healthy adult body, $90 \%$ of which distributes in bones and teeth $[5,6]$. A trace of fluorine is useful to prevent saprodontia but excessive amount tends to be harmful [7, 8]. It is supposed to be poisonous if the intake of fluorine is higher than $4 \mathrm{mg} / \mathrm{d}$; therefore, people are more likely to develop fluorosis of bone when the amount of fluorine in drinking water is more than $4 \mathrm{ppm}[9]$.

As the fluorine-containing substances are increasingly applied in industry, the amount of the fluorine-containing wasted water tends to become higher. Purification and defluoridation of high-fluorinated drinking water have drawn more and more attention. Conventional methods of defluoridation are precipitation and adsorption [10-13]. Adsorption method is mainly used in the deep disposal of low fluorinecontaining waste water and natural water. Because the adsorption method of disposing fluorine-containing waste water has the advantages of lower cost and higher removal rate [14], the modification of traditional fluorine removal agent and the research of new fluorine removal materials are popular topic in relative area [15-17]. Traditional fluorine removal agents include alumina, natural zeolite, and rare earth while the new adsorbent with good adsorption effects is calcium aluminate slag, aluminum sulfate modified bamboo charcoal, and bone charcoal [18-23]. In the midst of these adsorbents, bone charcoal is now considered to be one of the most recommendatory adsorbents in defluoridation since World Health Organization regarded bone charcoal as 

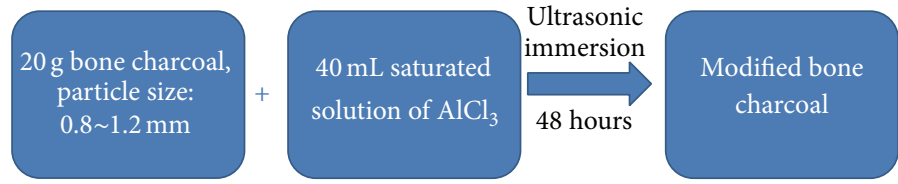

FIGURE 1: Manufacturing approach of aluminum-impregnated bone charcoal.

the high-performance absorbent of fluorion in undeveloped regions [24]. Based on this reason, we aimed at studying the defluoridation effect of bone charcoal and finding out the mechanism of the modification and adsorption.

Bone charcoal is a porous, black, granular material produced by charring animal bones [25]. It is made up of hydroxyapatite $(57-80 \%)$, calcium carbonate $(6-10 \%)$, and activated carbon (7-10\%). In the development of purification, bone charcoal was primarily used for filtration and decolourisation, which can also adsorb a large quantity of pollutants like pigments as well as fluorinion from water [26]. Based on the absorption theory, the hydroxylapatite in bone chars can be used to remove fluoride and metal ions from water, making it useful for the treatment of drinking supplies.

Adsorption is a separation method with the equilibrium principle. The main components of bone charcoal are hydroxyapatite. The mechanism of the removal of fluorine is mainly the adsorption and ion exchange reaction, which is shown as follows:

$$
\mathrm{Ca}_{10}\left(\mathrm{PO}_{4}\right)_{6}(\mathrm{OH})_{2}+2 \mathrm{~F}^{-} \longrightarrow \mathrm{Ca}_{10}\left(\mathrm{PO}_{4}\right)_{6} \mathrm{~F}_{2}+2 \mathrm{OH}^{-}
$$

Previous research [27] reported that, being immersed in aluminum solution for certain temporal, bone charcoal can be modified. The aluminum can impregnate onto the surface of bone charcoal, improving the effect of the defluoridation, which is the main core of our work. However, although this novel modified approach to optimize the performance of aluminum-impregnated bone charcoal in defluoridation has been discovered, the mechanism of the modification is still undefined. It is undoubtedly a huge impediment for us to explore the further studies of modified adsorbent. Therefore, we paid our attention to construct a probable reaction during the modified process in order to resolve this crucial problem.

Infrared spectroscopy is one of the most common analytic techniques in material characterization [28]. It is the spectroscopy that deals with the infrared region of the electromagnetic spectrum, with longer wavelength and lower frequency compared to the visible light. It covers a range of techniques, mostly based on absorption spectroscopy. As with all spectroscopic techniques, it can be used to study chemicals and relative substances [29]. In recent years, there are more and more explorations of reaction mechanism detected by spectroscopic methods [30-37]. Green and his coworkers [30] obtained the information of dual catalytic sites during oxidation of $\mathrm{CO}$ on $\mathrm{Au} / \mathrm{TiO}_{2}$ catalyst by spectroscopic observation. Roithová [31] concluded the characterization approaches of reaction intermediates by ion spectroscopy. Acik and his coworkers [32] have detected the role of oxygen during thermal reduction of graphene oxide using infrared absorption spectroscopy. Black and his coworkers [33] used spectroscopic method to screen for superoxide reactivity in $\mathrm{Li}-\mathrm{O}_{2}$ batteries. Chen and his coworkers [34] used FT-IR spectroscopy as a part of the instruments to determine mechanisms in water-gas-shift reaction on $\mathrm{Au} / \mathrm{CeO}_{2}$. Huang and his coworkers [35] utilized surface-enhanced Raman spectroscopy to study paminothiophenol. Costa and his coworkers [36] used relative spectroscopic methods to determine the clues to the internal barrier layer capacitance mechanism. Xu and his coworkers [37] clarified the thermal deterioration mechanism of bio-oil pyrolyzed from rice husk using Fourier transform infrared spectroscopy. The common point of the studies listed above is that all of them utilized the relative spectroscopic approaches to determine or infer the mechanism of the chemical reaction and process, proving that the spectroscopy is an available approach to estimate the mechanism of chemical reactions. What is worth mentioning is that all of these listed researches were published in the recent three years, showing that using spectroscopic approaches to establish the conjecture of chemical reactions is becoming a popular method among relative academic fields. Since detecting the modified mechanism of aluminum-impregnated bone charcoal and calculating the main reaction process by the modeling approach are difficult, in our study, we innovatively used infrared spectroscopy to obtain the infrared spectrums of the modified bone charcoal and the unmodified one, so that the mechanism can be inferred during the change of the modification.

\section{Materials and Methods}

2.1. Material Source and Treatment. Raw materials of bone charcoal in our experiments were supplied by Langfang Huaya Water Treatment Ltd., Hebei Province, China. All the bone charcoals were sieved by screens, of which the granularity is approximately from 0.8 to $1.2 \mathrm{~mm}$. Because of the adsorption mechanism shown in (1), alkaline environment of solution can provide a better effect of defluoridation; thus to ensure the good adsorbability materials were firstly immersed in saturated solution of sodium hydrate for 12 hours and then immersed in deionized water for 12 hours. After repetitive scrubbing, these raw bone charcoals were stoved by electric thermostatic drying oven under the temperature of $120^{\circ} \mathrm{C}$. Afterwards, the bone charcoals were sealed in the desiccator.

The manufacturing approach of aluminum-impregnated bone charcoal in our study met the standards of modified approaches created by previous studies. $20 \mathrm{~g}$ bone charcoal was immersed in $40 \mathrm{~mL}$ saturated solution of $\mathrm{AlCl}_{3}$, and the modification system was immersed in the ultrasonic oscillator, so that aluminum ion can impregnate onto the bone charcoal better. The modification procedure is shown in Figure 1. 


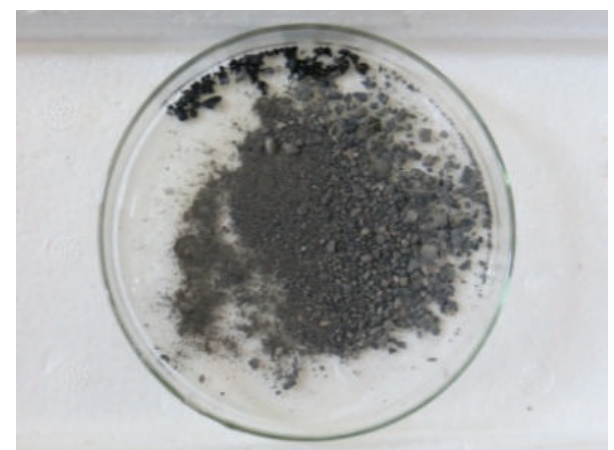

FIgURE 2: Aluminum-impregnated bone charcoal.

To guarantee the modification, we chose the saturated solution so the aluminum ion can impregnate onto the bone charcoal during the process of ultrasonic immersion. The dried aluminum-impregnated bone charcoal is shown as Figure 2.

The aluminum-impregnated bone charcoal takes on a color of silvery white and grey, while the unmodified bone charcoal is atrous. The change of macroscopic features can be observed obviously from this characteristic.

For comparison, we also designed a series of other modified bone charcoals. After the testing results, ferriimpregnated bone charcoal and magnesium-impregnated bone charcoal are also considered to be good modified adsorbents, with high removal rates of fluorinion. Therefore, we used these two modified bone charcoals together with the blank control group (those ultrasonic immersed in the saturated solution of sodium hydroxide) as the control groups in the analysis of adsorption isotherm (see Section 3.1: Adsorption Isotherm).

2.2. Preparation of Fluoride Solution. The sodium fluoride (NaF, AR) with deionized water configured to stock fluorinion solution of $1.0 \mathrm{~g} / \mathrm{L}$. Then it was diluted to be $5.0 \mathrm{mg} / \mathrm{L}$, as to be used for the follow-up test. This actual initial mass concentration was determined by fluoride selective electrode.

2.3. Adsorption Isotherms. To test the rationality of choosing aluminum-impregnated bone char as the object of study, we chose ferri-impregnated bone charcoal, aluminumimpregnated bone charcoal, and magnesium-impregnated bone charcoal as the main objects of studying the adsorption isotherms. All the metal-modified bone charcoals were modified under the same conditions and procedures. In addition, those raw bone charcoals immersed in the saturated solution of sodium hydroxide ultrasonically were taken as the blank control group. In the midst of these four types of bone charcoal, each kind of bone charcoals was divided into 6 groups, respectively: $0.2,0.4,0.8,1.2,1.6$, and $2.0 \mathrm{~g}$. After three-hour defluoridation, adsorption isotherms were developed during sample analysis.

\section{Results and Discussion}

3.1. Adsorption Isotherm. Previous studies show that the adsorption process of bone charcoal is corresponded with

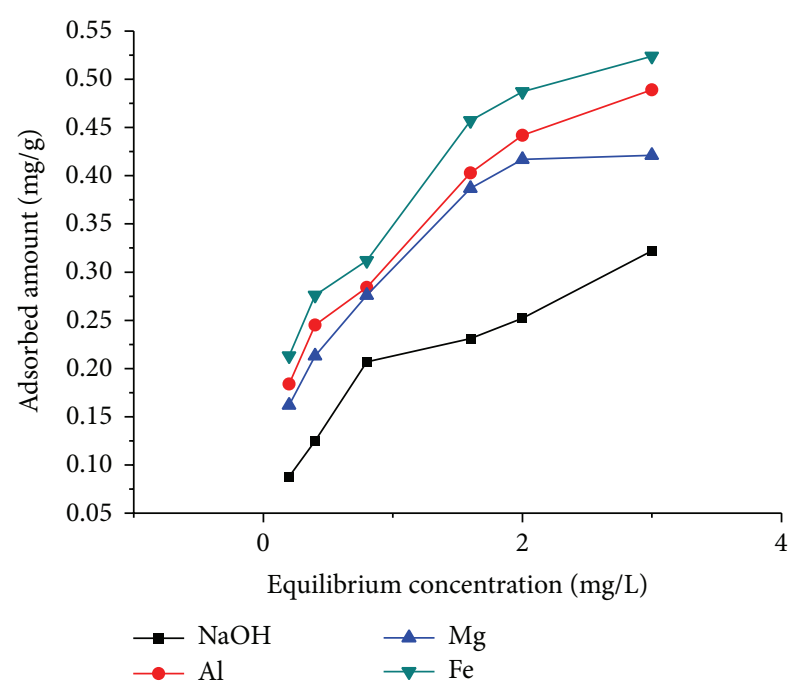

FIGURE 3: Adsorption isotherms of different modified bone charcoals in defluoridation.

Langmuir isotherm [38-41], which is an ordinary adsorption process of general adsorbents. For a better comparison, several modification experiments with different immersed ions were done and we obtained the adsorption isotherms for different ion-modified bone charcoal in defluoridation, which is shown in Figure 3 (blank control group: bone charcoal immersed in saturated solution of sodium hydrate).

Results shown in Figure 3 indicate the descending order of the corresponding defluoridation efficiency as follows: ferri-impregnated bone charcoal, aluminum-impregnated bone charcoal, magnesium-impregnated bone charcoal, and sodium hydrate immersed bone charcoal. Nevertheless, our experimental results are quite different from Shen's previous study [42]. In Shen's study, the defluoridation effect of aluminum bone charcoal is higher than those of ferriimpregnated bone charcoal. However, due to the different source of raw bone charcoals and the precise procedure of our modification experiments, we considered our results are accurate and reliable.

Although ferri-impregnated bone charcoal had the best defluoridation effect in our experiments, however, ferri ion is toxic and harmful to human body, which means that it cannot be applied to the practical applications [43]. Therefore, aluminum-impregnated bone charcoal is still the most rational option for defluoridation. Besides, results also prove that the aluminum-impregnated bone charcoal of our research is effective and can be used for further studies of the modified mechanism.

3.2. Infrared Spectroscopic Study on Aluminum-Impregnated Bone Charcoal. In order to study the modified mechanism of aluminum-impregnated bone charcoal, two samples from the same raw bone charcoal were determined by infrared spectrum. Figure 4 shows the infrared spectrum of raw bone charcoal without modification, while Figure 5 shows the infrared spectrum of aluminum-impregnated bone charcoal. 


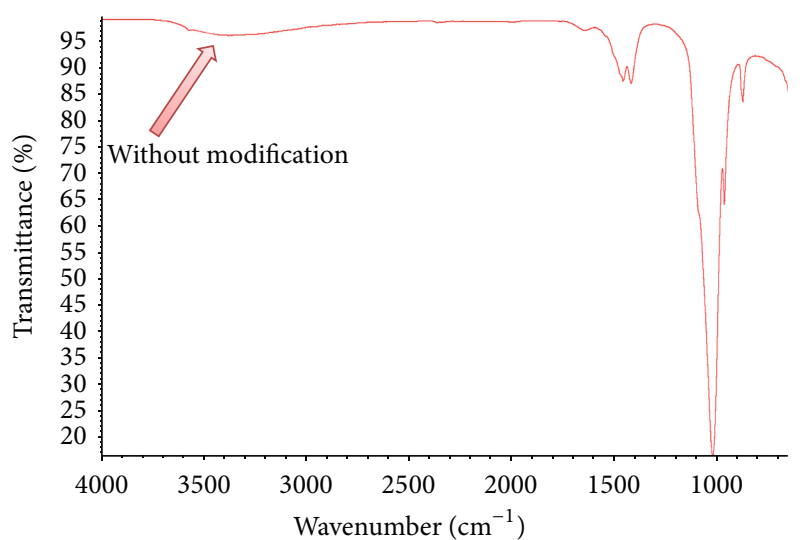

FIGURE 4: Infrared spectrum of bone charcoal without modification.

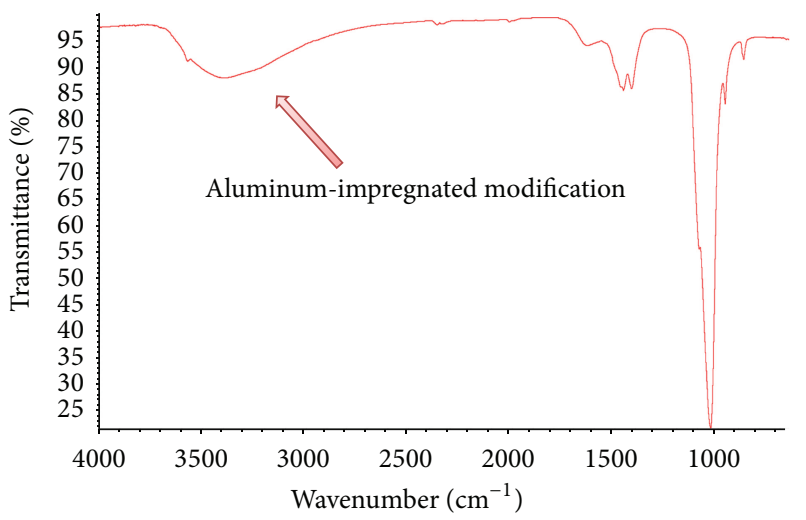

FIGURE 5: Infrared spectrum of aluminum-impregnated bone charcoal.

Figures 4 and 5 show the infrared spectrums of the two samples of bone charcoal, respectively. It is obvious that there are some differences of the peaks between the two infrared spectrums. The arrow heads in Figures 4 and 5 are the indexes of these main differences. In order to present these differences in a more evident way, Figures 4 and 5 were overlapped into the one picture, which is shown in Figure 6.

Figure 6 depicts an interesting phenomenon: after modification, in the stretching vibration area of hydrogen bond held together with $-\mathrm{OH}$, intensity of the typical absorption band of hydroxyapatite $\left(3400 \mathrm{~cm}^{-1}\right.$ nearby) $[44,45]$ has risen obviously. In contrast, other peaks have tiny significant change. This strange phenomenon attracted our attention: under the theoretically dry condition, how to explain this bizarre change of the peak?

To explain the interesting phenomenon presented in Figure 6, we should consider the possible reaction between aluminum ion and bone charcoal at first. One of the most striking explanations of this phenomenon is that anion exchange has happened during the modified process. Hydroxide ion is dissociated from $\mathrm{Ca}-\mathrm{OH}$ during the anion exchange, elevating the $\mathrm{PH}$ value. Under this circumstance, aluminum ion can combine with hydroxyl ion, forming tetrahydroxoaluminate ion. Based on this conjecture, the

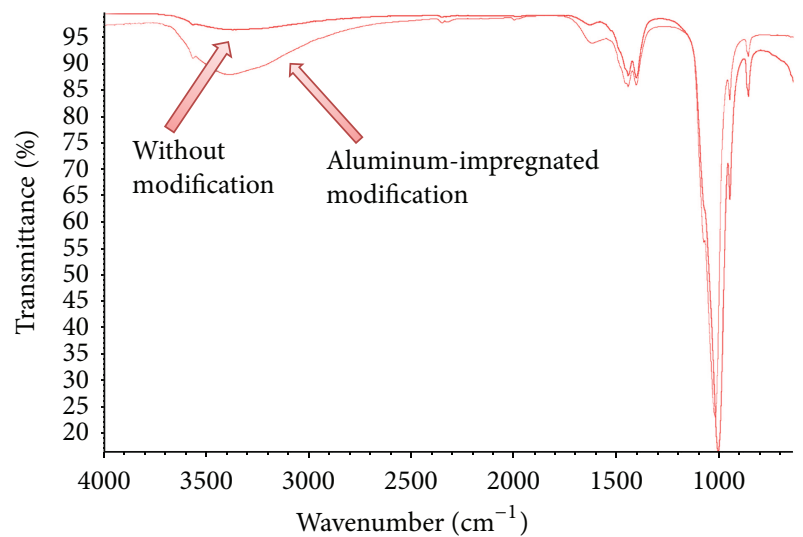

Figure 6: The overlapped infrared spectrum of Figures 4 and 5.

modified mechanism is constructed as the reaction shown as follows:

$$
\begin{aligned}
& \mathrm{Ca}_{10}\left(\mathrm{PO}_{4}\right)_{6}(\mathrm{OH})_{2}+\mathrm{Al}(\mathrm{OH})_{4}^{-} \\
& \longrightarrow \mathrm{Ca}_{10}\left(\mathrm{PO}_{4}\right)_{6} \mathrm{OH} \cdot \mathrm{Al}(\mathrm{OH})_{4}+\mathrm{OH}^{-}
\end{aligned}
$$

In previous study, Chen and her coworkers [46] offered an explanation for the mechanism of removal of arsenic (V) using bone charcoal as the adsorbent:

$$
\begin{aligned}
& \mathrm{Ca}_{10}\left(\mathrm{PO}_{4}\right)_{6}(\mathrm{OH})_{2}+\mathrm{HAsO}_{4}{ }^{2-} \\
& \longrightarrow \mathrm{Ca}_{10}\left(\mathrm{PO}_{4}\right)_{6}\left(\mathrm{HAsO}_{4}\right)+2 \mathrm{OH}^{-}
\end{aligned}
$$

Compared to our conjecture of the modified mechanism, Chen's research indicates that bone charcoal can arise from the ion exchange reaction during the adsorption, from which we can infer that the mechanism of adsorption and modification is extremely similar. In other words, during the modification process, aluminum ion can be "adsorbed" onto the surface of bone charcoal, and we deduce that this combination is stable and thus the aluminum can impregnate firmly.

As for the adsorption mechanism of aluminumimpregnated bone charcoal, Dong [47] offered an explanation for the high performance of the modified bone charcoal. This explanation discusses that because the aluminum ion has the unoccupied orbital, there exists the complex reaction between aluminum ion and fluorinion, and the maximum coordination number is considered to be six:

$$
\begin{aligned}
\mathrm{Al}^{3+}+\mathrm{F}^{-} & \longleftrightarrow \mathrm{AlF}^{2+} \\
\downarrow & \\
\mathrm{Al}^{3+}+2 \mathrm{~F}^{-} & \longleftrightarrow \mathrm{AlF}_{2}^{+} \\
\downarrow & \longleftrightarrow \mathrm{AlF}_{3}^{0} \\
\mathrm{Al}^{3+}+3 \mathrm{~F}^{-} & \longleftrightarrow \mathrm{AlF}_{4}^{-} \\
\downarrow &
\end{aligned}
$$




$$
\begin{aligned}
\downarrow & \\
\mathrm{Al}^{3+}+5 \mathrm{~F}^{-} & \longleftrightarrow \mathrm{AlF}_{5}{ }^{2-} \\
\downarrow & \\
\mathrm{Al}^{3+}+6 \mathrm{~F}^{-} & \longleftrightarrow \mathrm{AlF}_{6}{ }^{3-}
\end{aligned}
$$

Dong's explanation of aluminum-impregnated bone charcoal seems reasonable. However, according to our study, some of the unoccupied orbitals of the aluminum impregnated onto the bone charcoal had actually been occupied during the modified process. Therefore, the average maximum coordination number of aluminum in the aluminumimpregnated bone charcoal may be less than six. Based on our opinion, the adsorption mechanism explained by Dong [47] is not totally perfect, which may overestimate the adsorption effects of aluminum-impregnated bone charcoal. Our research indicates that, in the process of defluoridation, aluminum-impregnated bone charcoal is undergoing two kinds of adsorption process. On the one hand, hydroxyapatite in bone charcoal is undergoing the adsorption process as (1) presents; on the other hand, aluminum which has been impregnated onto the bone charcoal's surface is undergoing the process of coordination reaction: aluminum combines with fluorinion in a stable way.

According to previous studies [48-51], some similar researches on determining the mechanisms of different adsorbents were used to make comparison. Namasivayam and Kavitha [48] detected the adsorption interactions of dye, phenol, and chlorophenol onto coir pith carbon from aqueous solution using various detection techniques. Nadeem and his coworkers [49] detected the modified carbon adsorbents by SEM. In addition, Ahmad and Kumar [50] also utilize SEM to detect the adsorption information of amaranth dye onto alumina reinforced polystyrene. Gupta and his coworkers [51] detected the details about banana pseudostem fiber in the removal of harmful malachite green dye using Fourier transform infrared spectroscopy, scanning electron microscope, and X-ray diffractometer. These studies are advanced in detecting the properties of adsorbents which can seem as the excellent references. Nevertheless, these researches did not detect the adsorption processes of the modification mechanisms of the studied adsorbents by infrared spectroscopic methods. Hence, our research has successfully made up the blank of this area. According to the comparison, using infrared spectroscopy to detect and infer the modification mechanism of bone charcoal is proved to be effective and available.

\section{Conclusion}

Fluoride contamination is a prominent and widespread problem in many parts of the world. Such contamination in drinking water is mostly natural and unpreventable that affects the health for human beings. There is a common agreement that drinking fluoridated water can lead to a high risk of fluorosis in human body. To reduce the risk, metal-impregnated bone charcoal has been frequently used as an ideal material for fluoride removal. In this study, the defluoridation efficiency of the bone charcoals modified by different metal ions was investigated. Their adsorption isotherms help highlighting the descending order of the corresponding defluoridation efficiency as follows: ferri-impregnated bone charcoal, aluminum-impregnated bone charcoal, magnesium-impregnated bone charcoal, and sodium hydrate immersed bone charcoal. Considering the potential toxicity of ferri-impregnated bone charcoal, the aluminum-impregnated bone charcoal was adapted as the most rational adsorbent for defluoridation in our experiments. Its modified mechanism was further successfully explored using the infrared spectroscopy. The strengthening of the hydroxyl peak intensified in infrared spectrum was examined. The results imply that the probable modified reaction is ion exchange and tetrahydroxoaluminate can combine with hydroxyapatite, which in turn suggests that aluminum ion can be impregnated onto the surface of the bone charcoal. In future study, more attention deserves to be paid to the adsorption of lead and arsenic as some advanced researches provide great inspirations on the topic $[46,52-55]$.

\section{Conflict of Interests}

The authors declare that there is no conflict of interests regarding the publication of this paper.

\section{Authors' Contribution}

Hao Li and Yufan Yang contributed equally to this paper.

\section{Acknowledgment}

This work was supported by the Fund for Fostering Talents in Basic Science of the National Natural Science (Grant no. J1103315).

\section{References}

[1] P. J. Riordan, "Fluoride supplements for young children: an analysis of the literature focusing on benefits and risks," Community Dentistry and Oral Epidemiology, vol. 27, no. 1, pp. 72-83, 1999.

[2] R. C. Maheshwari, "Fluoride in drinking water and its removal," Journal of Hazardous Materials, vol. 137, no. 1, pp. 456-463, 2006.

[3] G. Rolla and E. Saxegaard, "Critical evaluation of the composition and use of topical fluorides, with emphasis on the role of calcium fluoride in caries inhibition," Journal of Dental Research, vol. 69, pp. 780-785, 1990.

[4] M. N. Anjum, M. T. Shah, F. Ali et al., "Geochemical studies of fluoride in drinking water of union council ganderi, district nowshera, Khyber Pakhtunkhwa, Pakistan," World Applied Sciences Journal, vol. 27, no. 5, pp. 632-636, 2013.

[5] D. Taylor, J. G. Hazenberg, and T. C. Lee, "Living with cracks: damage and repair in human bone," Nature Materials, vol. 6, no. 4, pp. 263-268, 2007.

[6] H. Yamamoto, Y. Iwami, T. Unezaki, Y. Tomii, and S. Ebisu, "Fluoride uptake in human teeth from fluoride-releasing restorative 
material in vivo and in vitro: two-dimensional mapping by EPMA-WDX," Caries Research, vol. 35, no. 2, pp. 111-115, 2001.

[7] K. K. Cheng, I. Chalmers, and T. A. Sheldon, "Adding fluoride to water supplies," British Medical Journal, vol. 335, no. 7622, pp. 699-702, 2007.

[8] X. Zhan, H. Xu, and G. Li, "The toxicity of sodium fluoride on pulmonary arterial smooth muscle cell proliferation," Chinese Journal of Control of Endemic Disease, vol. 6, p. 11, 2003.

[9] Y. Kim and F. P. Gabbai, "Cationic boranes for the complexation of fluoride ions in water below the $4 \mathrm{ppm}$ maximum contaminant level," Journal of the American Chemical Society, vol. 131, no. 9, pp. 3363-3369, 2009.

[10] N. Parthasarathy, J. Buffle, and W. Haerdi, "Combined use of calcium salts and polymeric aluminium hydroxide for defluoridation of waste waters," Water Research, vol. 20, no. 4, pp. 443448, 1986.

[11] A. K. Yadav, C. P. Kaushik, A. K. Haritash, A. Kansal, and N. Rani, "Defluoridation of groundwater using brick powder as an adsorbent," Journal of Hazardous Materials, vol. 128, no. 2-3, pp. 289-293, 2006.

[12] S. Jagtap, M. K. N. Yenkie, N. Labhsetwar, and S. Rayalu, "Defluoridation of drinking water using chitosan based mesoporous alumina," Microporous and Mesoporous Materials, vol. 142, no. 2-3, pp. 454-463, 2011.

[13] P. Loganathan, S. Vigneswaran, J. Kandasamy, and R. Naidu, "Defluoridation of drinking water using adsorption processes," Journal of Hazardous Materials, vol. 248-249, no. 1, pp. 1-19, 2013.

[14] A. Bhatnagar, E. Kumar, and M. Sillanpää, "Fluoride removal from water by adsorption-a review," Chemical Engineering Journal, vol. 171, no. 3, pp. 811-840, 2011.

[15] Y. Sun, Q. Fang, J. Dong, X. Cheng, and J. Xu, "Removal of fluoride from drinking water by natural stilbite zeolite modified with Fe(III)," Desalination, vol. 277, no. 1-3, pp. 121-127, 2011.

[16] Y. Nie, C. Hu, and C. Kong, "Enhanced fluoride adsorption using Al (III) modified calcium hydroxyapatite," Journal of Hazardous Materials, vol. 233-234, pp. 194-199, 2012.

[17] Q. Zhang, Q. Du, T. Jiao et al., "Rationally designed porous polystyrene encapsulated zirconium phosphate nanocomposite for highly efficient fluoride uptake in waters," Scientific Reports, vol. 3, pp. 1-9, 2013.

[18] E. Kumar, A. Bhatnagar, U. Kumar, and M. Sillanpää, "Defluoridation from aqueous solutions by nano-alumina: characterization and sorption studies," Journal of Hazardous Materials, vol. 186, no. 2-3, pp. 1042-1049, 2011.

[19] L. Gómez-Hortigüela, A. B. Pinar, J. Pérez-Pariente et al., "Ion-exchange in natural zeolite stilbite and significance in defluoridation ability," Microporous and Mesoporous Materials, vol. 193, pp. 93-102, 2014.

[20] A. M. Raichur and M. Jyoti Basu, "Adsorption of fluoride onto mixed rare earth oxides," Separation and Purification Technology, vol. 24, no. 1-2, pp. 121-127, 2001.

[21] M.-J. Bai and Y.-Y. Chu, "Removal of fluorine ions from wastewater using calcium aluminate slag," Environmental Science \& Technology, vol. 9, no. 34, pp. 117-120, 2008.

[22] Q. Zhang and G. Wang, "Research on removing effects of the bamboo-carbon for fluoride from drink water," Guangdong Weiliang Yuansu Kexue, vol. 12, no. 3, p. 63, 2005.

[23] C. K. Rojas-Mayorga, A. Bonilla-Petriciolet, I. A. AguayoVillarreal et al., "Optimization of pyrolysis conditions and adsorption properties of bone char for fluoride removal from water," Journal of Analytical and Applied Pyrolysis, vol. 104, pp. 10-18, 2013.

[24] J. K. Fawell, Fluoride in Drinking-Water, World Health Organization, 2006.

[25] M. E. Kaseva, "Optimization of regenerated bone char for fluoride removal in drinking water: a case study in Tanzania," Journal of Water and Health, vol. 4, no. 1, pp. 139-147, 2006.

[26] F. Ospitali, D. C. Smith, and M. Lorblanchet, "Preliminary investigations by Raman microscopy of prehistoric pigments in the wall-painted cave at Roucadour, Quercy, France," Journal of Raman Spectroscopy, vol. 37, no. 10, pp. 1063-1071, 2006.

[27] N. A. Medellin-Castillo, R. Leyva-Ramos, R. Ocampo-Perez et al., "Adsorption of fluoride from water solution on bone char," Industrial and Engineering Chemistry Research, vol. 46, no. 26, pp. 9205-9212, 2007.

[28] B. C. Smith, Fundamentals of Fourier Transform Infrared Spectroscopy, CRC Press, Boca Raton, Fla, USA, 2011.

[29] C. Krafft and V. Sergo, "Biomedical applications of Raman and infrared spectroscopy to diagnose tissues," Spectroscopy, vol. 20, no. 5-6, pp. 195-218, 2006.

[30] I. X. Green, W. Tang, M. Neurock, and J. T. Yates Jr., "Spectroscopic observation of dual catalytic sites during oxidation of CO on a $\mathrm{Au} / \mathrm{TiO}_{2}$ catalyst," Science, vol. 333, no. 6043, pp. 736-739, 2011.

[31] J. Roithová, "Characterization of reaction intermediates by ion spectroscopy," Chemical Society Reviews, vol. 41, no. 2, pp. 547559, 2012.

[32] M. Acik, G. Lee, C. Mattevi et al., "The role of oxygen during thermal reduction of graphene oxide studied by infrared absorption spectroscopy," The Journal of Physical Chemistry C, vol. 115, no. 40, pp. 19761-19781, 2011.

[33] R. Black, S. H. Oh, J.-H. Lee, T. Yim, B. Adams, and L. F. Nazar, "Screening for superoxide reactivity in $\mathrm{Li}-\mathrm{O}_{2}$ batteries: effect on $\mathrm{Li}_{2} \mathrm{O}_{2} / \mathrm{LiOH}$ crystallization," Journal of the American Chemical Society, vol. 134, no. 6, pp. 2902-2905, 2012.

[34] Y. Chen, H. Wang, R. Burch, C. Hardacre, and P. Hu, "New insight into mechanisms in water-gas-shift reaction on $\mathrm{Au} / \mathrm{CeO}_{2}(111)$ : a density functional theory and kinetic study," Faraday Discussions, vol. 152, pp. 121-133, 2011.

[35] Y.-F. Huang, D.-Y. Wu, H.-P. Zhu et al., "Surface-enhanced Raman spectroscopic study of p-aminothiophenol," Physical Chemistry Chemical Physics, vol. 14, no. 24, pp. 8485-8497, 2012.

[36] S. I. R. Costa, M. Li, J. R. Frade, and D. C. Sinclair, "Modulus spectroscopy of $\mathrm{CaCu}_{3} \mathrm{Ti}_{4} \mathrm{O}_{12}$ ceramics: clues to the internal barrier layer capacitance mechanism," RSC Advances, vol. 3, no. 19, pp. 7030-7036, 2013.

[37] F. Xu, Y. Xu, R. Lu, G.-P. Sheng, and H.-Q. Yu, "Elucidation of the thermal deterioration mechanism of bio-oil pyrolyzed from rice husk using fourier transform infrared spectroscopy," Journal of Agricultural and Food Chemistry, vol. 59, no. 17, pp. 9243-9249, 2011.

[38] G. Ghanizadeh and G. Asgari, "Adsorption kinetics and isotherm of methylene blue and its removal from aqueous solution using bone charcoal," Reaction Kinetics, Mechanisms and Catalysis, vol. 102, no. 1, pp. 127-142, 2011.

[39] J. A. Wilson, I. D. Pulford, and S. Thomas, "Sorption of Cu and $\mathrm{Zn}$ by bone charcoal," Environmental Geochemistry and Health, vol. 25, no. 1, pp. 51-56, 2003.

[40] M. T. Ghaneian, G. Ghanizadeh, M. T. H. Alizadeh et al., "Equilibrium and kinetics of phosphorous adsorption onto bone charcoal from aqueous solution," Environmental Technology, vol. 35, no. 7, pp. 882-890, 2014. 
[41] C. W. Cheung, C. K. Chan, J. F. Porter, and G. Mckay, "Combined diffusion model for the sorption of cadmium, copper, and zinc ions onto bone char," Environmental Science \& Technology, vol. 35, no. 7, pp. 1511-1522, 2001.

[42] X. W. Shen, Research on the Defluoridation of Bone Charcoal in Low Concentration Wastewater, Jiangxi University of Technology, 2011.

[43] B. Halliwell, "Antioxidants in human health and disease," Annual Review of Nutrition, vol. 16, pp. 33-50, 1996.

[44] J. G. Wu, Modern FTIR Technology and Application, vol. 35, Science and Technology Literature Press, Beijing, China, 1st edition, 1994.

[45] Y. Mikhaylova, G. Adam, L. Häussler, K.-J. Eichhorn, and B. Voit, "Temperature-dependent FTIR spectroscopic and thermoanalytic studies of hydrogen bonding of hydroxyl (phenolic group) terminated hyperbranched aromatic polyesters," Journal of Molecular Structure, vol. 788, no. 1-3, pp. 80-88, 2006.

[46] Y.-N. Chen, L.-Y. Chai, and Y.-D. Shu, "Arsenic(V) removal from drinking water by bone char," Journal of Central South University (Science and Technology), vol. 39, no. 2, pp. 279-283, 2008 (Chinese).

[47] S. M. Dong, Research on Defluoridation in Water and Soil System the Removal Mechanism, Changan University, 2004.

[48] C. Namasivayam and D. Kavitha, "IR, XRD and SEM studies on the mechanism of adsorption of dyes and phenols by coir pith carbon from aqueous phase," Microchemical Journal, vol. 82, no. 1, pp. 43-48, 2006.

[49] M. Nadeem, A. Mahmood, S. A. Shahid, S. S. Shah, A. M. Khalid, and G. McKay, "Sorption of lead from aqueous solution by chemically modified carbon adsorbents," Journal of Hazardous Materials, vol. 138, no. 3, pp. 604-613, 2006.

[50] R. Ahmad and R. Kumar, "Adsorption of amaranth dye onto alumina reinforced polystyrene," Clean-Soil, Air, Water, vol. 39, no. 1, pp. 74-82, 2011.

[51] N. Gupta, A. K. Kushwaha, and M. C. Chattopadhyaya, "Adsorption of brilliant green dye from aqueous solution by banana pseudo-stem fibers," Journal of the Indian Chemical Society, vol. 89, no. 7, pp. 891-902, 2012.

[52] Q. Zhang, Q. Du, M. Hua, T. Jiao, F. Gao, and B. Pan, "Sorption enhancement of lead ions from water by surface charged polystyrene-supported nano-zirconium oxide composites," Environmental Science \& Technology, vol. 47, no. 12, pp. 6536-6544, 2013.

[53] Q. Peng, J. Guo, Q. Zhang et al., "Unique lead adsorption behavior of activated hydroxyl group in two-dimensional titanium carbide," Journal of the American Chemical Society, vol. 136, no. 11, pp. 4113-4116, 2014.

[54] M. B. Baskan and A. Pala, "Batch and fixed-bed column studies of arsenic adsorption on the natural and modified clinoptilolite," Water, Air, \& Soil Pollution, vol. 225, no. 1, pp. $1-10,2014$.

[55] K. Kwok, L. F. Koong, G. Chen et al., "Mechanism of arsenic removal using chitosan and nanochitosan," Journal of Colloid and Interface Science, vol. 416, pp. 1-10, 2014. 

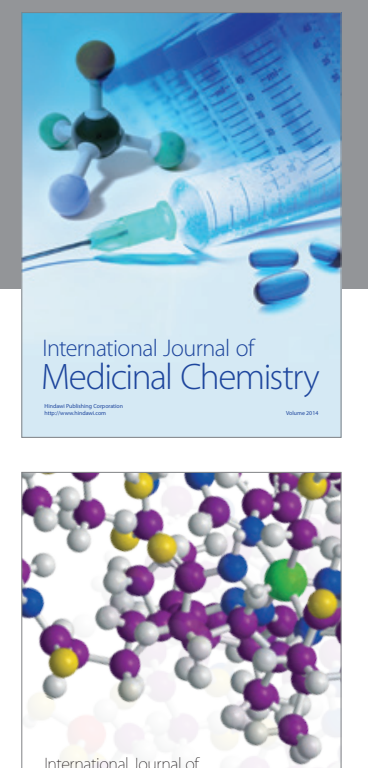

\section{Carbohydrate} Chemistry

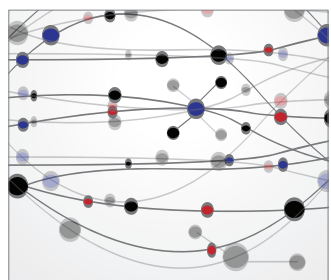

The Scientific World Journal
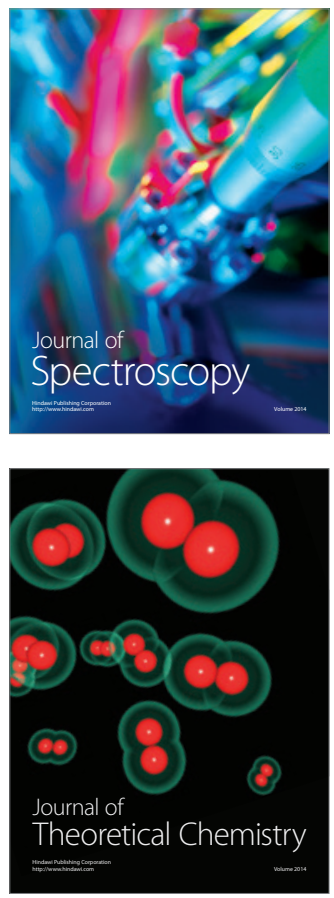
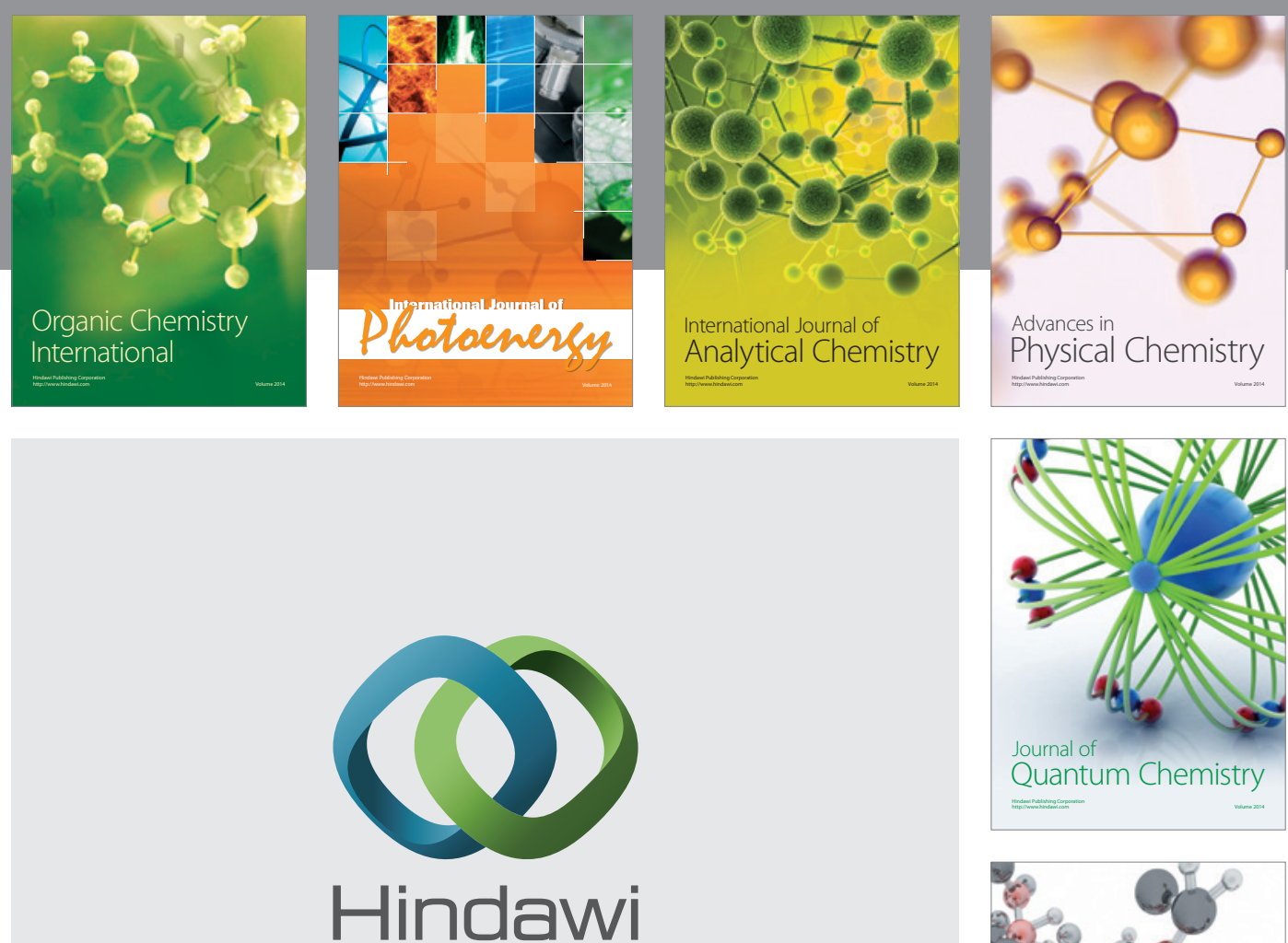

Submit your manuscripts at

http://www.hindawi.com

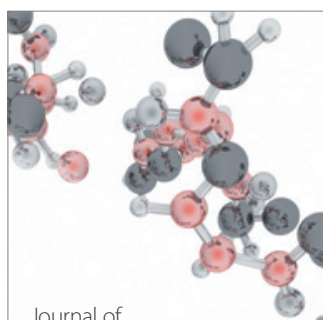

Analytical Methods

in Chemistry

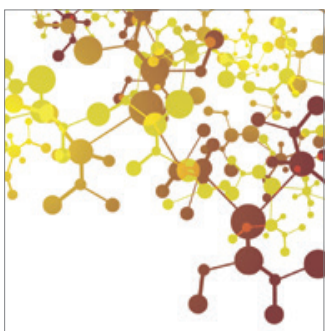

Journal of

Applied Chemistry

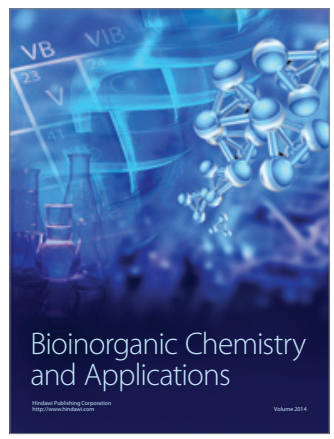

Inorganic Chemistry
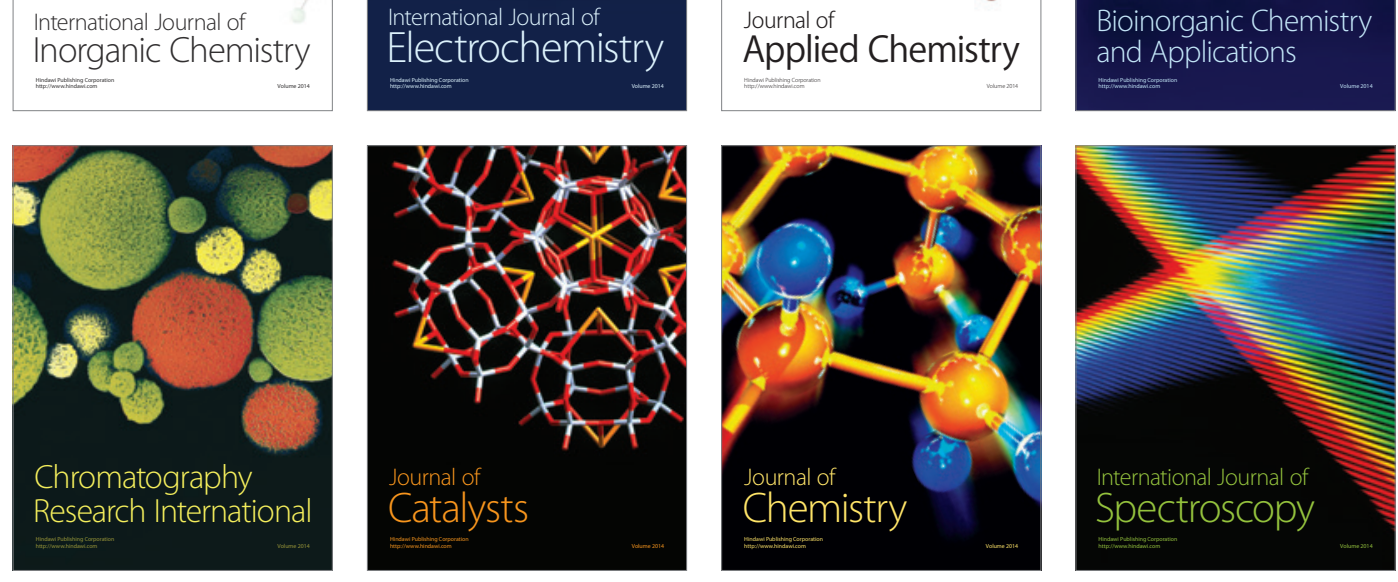